\title{
La primera edición hispana del Pro Archia a cargo de Francisco Cervantes Salazar (Sevilla 1544): aproximación a su estudio y posibles modelos $^{1}$
}

\author{
Manuel Ayuso García ${ }^{2}$
}

Recibido: 30 de junio de 2020 / Aceptado: 3 de septiembre de 2020

Resumen. En el presente trabajo se estudia esta edición y comentario, muy poco conocida, de la que solo se conserva un ejemplar en la Biblioteca de la Universidad de Salamanca, poniendo especial atención en los posibles modelos textuales dentro de la tradición impresa del texto ciceroniano. La obra incorpora varios paratextos reveladores, en particular unas introducciones y el comentario cuyos modelos, conocidos solo en parte, he aclarado. Esta edición denota un buen conocimiento de la obra de Cicerón y de los trabajos editados sobre la misma hasta entonces. El análisis de la tradición impresa anterior nos ha permitido identificar los principales rasgos de la forma textual de esta edición, que parte del texto y comentario de F. Dubois, Paris 1530, pero también de otras fuentes como las ediciones de Melanchthon, Latomus, Bolerus y otros.

Palabras clave. Ediciones y comentarios renacentistas; Pro Archia; Francisco Cervantes Salazar; La imprenta española en sus primeros tiempos.

\section{[en] The first Spanish edition of Pro Archia by Francisco Cervantes Salazar (Seville 1544): approaching study and possible models}

\begin{abstract}
This very scarcely known edition and comment, whose only preserved copy is in University Library of Salamanca, is studied in this paper, paying special attention to the possible textual models from the Ciceronian printed text transmission. The work includes several meaningful paratexts, particularly some prefaces and the comment, whose models -only partially known- I have tried to reveal. This edition demonstrates a good knowledge of Cicero's speech and works concerning it so far published. The analysis of printed text tradition taken from earlier years has allowed me to identify main features of textual form in this edition whose most immediate source is the Pro Archia text and comment by F. Dubois (Paris 1530), but also from some other sources as Melanchthon, Latomus, Bolerus and others. Keywords. Renaissance editions and commentaries; Pro Archia; F. Cervantes Salazar. Spanish early print.
\end{abstract}

\footnotetext{
Este trabajo es fruto de los Proyectos de Investigación "Estudio filológico de los textos clásicos latinos transmitidos en impresos incunables y postincunables conservados en España" (PGC 2018-094609-B-I00, cofinanciado por el Ministerio de Ciencia e Innovación y el Fondo Europeo de Desarrollo Regional, FEDER) y "Las ediciones de los clásicos latinos en el Renacimiento: tipología de los paratextos y su integración en la base de datos de BECLaR" (ref. PR[19]_CLA_0084, del Programa Logos, Fundación BBVA de ayudas a la investigación en el área de Estudios Clásicos).

2 UNED

Correo electrónico: mayuso@flog.uned.es.
} 
Sumario. 1. Introducción. 2. Datos de la edición. 3. El Texto y comentario. 4. Conclusiones. 5. Referencias bibliográficas. 6 . Apéndices.

Cómo citar: Ayuso García, M. «La primera edición hispana del Pro Archia a cargo de Francisco Cervantes Salazar (Sevilla 1544): aproximación a su estudio y posibles modelos», Cuad. Filol. Clás. Estud. Lat. 40.2 (2020), 247-270.

\section{Introducción}

Entre los impresos hispanos antiguos de clásicos latinos se encuentra la edición sevillana de 1544 del Pro Archia, con introducción y comentario a cargo de Francisco Cervantes Salazar (en adelante FCS), apenas conocida hasta el momento, pues no es citada en ninguno de los grandes catálogos de ediciones de este periodo ${ }^{3}$. Al escaso conocimiento de este impreso ha contribuido el hecho de que solo se conserva un único ejemplar de esta edición en la Biblioteca de la Universidad de Salamanca ${ }^{4}$. El comentario y el volumen en el que se conserva muestran una claro vínculo de la edición estudiada y su uso con el estudio de la retórica, relacionada estrechamente en la España de los ss. XVI y XVII con los progymnasmata, como señalan Arcos (2015), López Grigera (1994) o Clark (1952). La pretensión de este trabajo es analizar la edición, tratar de identificar sus modelos inmediatos y comprobar de qué modo se han integrado en la misma.

Este impreso forma parte de la tradición de los comentarios y ediciones del Pro Archia producidos en el Renacimiento ${ }^{5}$, cuya relación se recoge en el apéndice 6.7. de este trabajo, una tradición propuesta que cobró vigor desde el descubrimiento por parte de Petrarca en 1333 de una copia del discurso en Lieja y su posterior difusión por Italia y, desde allí, por el resto de Europa como señala McLaughlin (2015, 17$38)^{6}$. La recepción de la obra oratoria y retórica de Cicerón, así como la transmisión manuscrita del Pro Archia ha sido objeto de recientes estudios que han dado lugar a la propuesta de un nuevo stemma $\mathrm{m}^{7}$. Sin embargo, la transmisión impresa aún carece de un estudio de conjunto ${ }^{8}$. Desde la invención de la imprenta hasta la fecha de pu-

3 No hay entrada de esta edición en USTC (Universal Short Title Catalogue), IB (Iberian Books) o CCPBE (Catálogo Colectivo del Patrimonio Bibliográfico Español). Consultado [15-06-2019]. Tras la redacción del trabajo se ha publicado el catálogo de Castillejo, que incorpora esta edición $(2019,499)$. Asimismo se ha publicado también en este periodo el repositorio digital CECLE, dentro del Proyecto BECLaR, que también lo recoge, http://www.incunabula.uned.es/CECLE0198.

4 El volumen facticio que lo transmite, con signatura BG/21825, también contiene el único testimonio de la edición de Juan Lorenzo Palmireno de la versión latina de Cataneo de los Progymnasmata de Aftonio, Valencia en 1552, cf. Arcos (2017, 105-118).

5 Sobre la influencia de los comentarios en la recepción y transmisión de los clásicos, $c f$. Enenkel (2014), en especial pp. 1-12.

Para el caso específico del Pro Archia, cf. (Keyser, 2013, 292-328).

cf. en particular Keyser (2013, 292-232) y Keyser, Deneire (2013, 193-208).

Sobre la recepción de Cicerón se han publicado en los últimos años diversos trabajos entre los cuales destaco los siguientes: Cox, Wards (2006); Altmann (2015); Marsh (2011, 306-317). Sobre la bibliografía reciente de la obra oratoria de Cicerón resulta de utilidad la selección propuesta por Graig $(2002,503-600)$, en particular la bibliografía recogida en dicho volumen, pp. 533-600. 
blicación del impreso de FCS el discurso ciceroniano se imprimió cerca de un centenar de veces ${ }^{9}$. Pues bien, en este trabajo me propongo estudiar cómo se inserta esta edición dentro de la tradición impresa y analizar sus características más relevantes.

\section{Datos Generales de la edición}

De esta edición no da cuenta hasta el momento ninguna de las grandes obras de referencia de las ediciones del s. XVI y solamente he constatado un registro de la misma en el catálogo en línea de la BU de Salamanca, BG/21825(7).

Se trata de una edición en octavo, impresa en los talleres sevillanos de Dominicus de Robertis en el año de $1544^{10}$. Los datos fundamentales de descripción bibliográfica de este impreso, cuyas imágenes pueden verse en el apéndice 6.1., son los siguientes:

a. Portada: M.T.C. ORA:|TIO PRO ARCHIA POETA| DOCTORVM VIRORVM | SCHOLIIS, ADIECTIS| QVIBVSDAM FRAN-|CISCI CERVAN-|TIS SANAZARI| ELVCIDATIO-|NIBVS ILLU|STRATA [marca del impresor] | 1544. [h. alr].

b. Impresor: Dominicus de Robertis. La marca del impresor es un grifo sobre un libro y este sobre una bola del mundo alada con las iniciales "D.R." [h. a1r], pero el nombre se cita en el colofón [h. b8r].

c. Fecha: 1544, lugar de impresión: Sevilla. La fecha está estampada en la portada [h. a1r] y el lugar en el colofón [h. b8r]

d. Íncipit: [h. a2r]: [corazoncillo] FRANCIS-|CVS CERVANTES SANAZARvS| HVMANISSIMO LE- |CTORI. S. | CVM HISCE DIEBVS, LECTOR| humanissime, breuem quandam Ioachimi rhetoricam ....

e. Colofón: [h. b8r]: [corazoncillo] EXCUVDEBAT HISPALI | DOMINICVS DE | ROBERTIS.

f. Descripción: $8^{\circ} ; 16$ [16] h.; colación: a-b8; 29 líneas por plana; texto a dos columnas. Tipografía redonda romana para el comentario, encabezamientos y colofón y cursiva itálica para texto de Cicerón, prefacio y argumento.

g. Contenidos: h. a1r: Portada. h. a2r: Prefacio al lector de h. Cervantes. h. a2v: Argumentum de h. Cervantes. hh. a3r-v: Dispositio ex probatissimis authoribus. hh. a4r-b8r: texto y comentario. h. b8r colofón.

La edición recoge, en efecto, el discurso de Cicerón acompañado de comentarios y anotaciones al texto del Pro Archia debidos a otros eruditos - calificados como docti viri- así como aclaraciones del propio FCS. Cada una de las entradas del comentario comienza con un calderón, las palabras comentadas y cierre de paréntesis, forma habitual en los impresos semejantes de la época. Cuando es preciso, la columna del

\footnotetext{
Al final de este trabajo (Apéndice 6.7) se ha incluido una lista con las ediciones exentas del discurso, con o sin comentario, impresas entre 1484 y 1543 y las más significativas de las que contienen el Pro Archia, pero faltan por añadir muchas ediciones que transmiten el discurso, que suman también varias decenas.

10 Se puede descargar la reproducción digital de la misma en formato pdf desde esta dirección: https://gredos.usal. es/jspui/handle/10366/137628. He optado por hacer una transcripción diplomática de los textos tomados de esta y de las demás ediciones antiguas, reproduciendo evidentes erratas y manteniendo los textos griegos solo con los diacríticos que contiene el original.
} 
comentario o la del texto ocupa el espacio de la otra. Así sucede en h. a6r con el comentario que se extiende ocupando el sitio del texto. O viceversa en la última página, h. b8r, con la columna del texto de Cicerón que en 11 líneas se extiende al lugar que dejan los huecos de la columna de los comentarios. Esta práctica se debe a la falta de espacio ante la necesidad de terminar en esta hoja la impresión para ajustarse al número de cuadernillos previstos, esto es, dos.

El aspecto de la edición es muy sobrio, carece de capitales xilografiadas y otras xilografías a excepción de la marca del impresor, que recuerda en su diseño a la del taller lionés de Griphius con el añadido de las iniciales D R, acaso para distinguirse. No obstante, los títulos y colofón están precedidos por corazoncillos y el tamaño de la tipografía decreciente forma un triángulo que decora la portada, el título del prefacio y el colofón.

El único ejemplar localizado hasta la fecha que transmite la edición es el preservado en la BU de Salamanca, con signatura BG/21825(7), el cual forma un volumen facticio con otras ocho obras más. De las nueve obras, ocupa la séptima posición ${ }^{11}$. El ejemplar se conserva en buen estado con escasas manchas de humedad y buena legibilidad. Este volumen, que contiene obras editadas entre 1528 y 1598, parece una composición para uso académico en la que todas las obras están en latín, salvo una en griego. Al menos cuatro de ellas tienen relación directa con la retórica. Este conjunto transmite también algunas glosas manuscritas y subrayados de una mano antigua sin identificar.

Para hacer un análisis de esta edición, veamos ahora los datos más relevantes, relacionados con el impresor, el editor y las características del texto y comentarios.

\subsection{El impresor Dominico de Robertis}

Los primeros datos que conviene destacar son estos: se trata de una impresión sevillana salida de las prensas de Dominicus o Dominico de Robertis, impresor activo en Sevilla en el segundo tercio del siglo XVI, de probable origen italiano ${ }^{12}$.

Las ediciones a cargo de este impresor o taller fluctúan según las fuentes. Del mismo la Biblioteca Virtual Cervantes enumera 7 ediciones, el repositorio de catálogos Worldcat: 5, CCPBE: 4, BSB: 6, BNF: 11, BL: 16 y la $B N E: 28$, situadas entre 1534, fecha en la que aparece el título, De rosa et partibus eius : de succi rosarum temperatura, nec non De rosis Persicis, quas Alexandrinas vocant, libellus / Nicolao Monardo [...] auctore, y 1554, en la que se imprime, In sacrosancta Iesu Christi

11 Las obras que acompañan al Pro Archia, cuyos titulos se trasncriben paleográficamente, son las siguientes: 1) BG/21825(1), Marci Tullii Ciceronis Orpheus: siuè de Adolescente studioso, ad Marcum filium Athenas. (Ve-

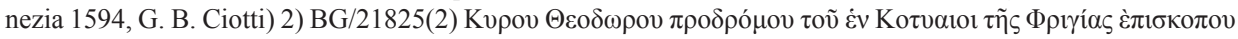
$\pi$ oté $\mu \alpha \tau \alpha$ [Kyrou Theodorou Prodromou tou en Kotyaioi tes Phrygias episkopou Poiemata] = Cyri Theodori Prodromi Prodromus, Theodorus. (Leipzig 1598,V. Vögelin). 3) BG/21825(3) Cornelius Nepos De viris illustribus (Lyon 1543, J. Frellon). 4) BG/21825(4) Querela pacis: undique gentium eiectae profligataeque / autore Des[iderio] Erasmo Rot[erodamo. (Lyon 1529, S. Gryphius). 5) BG/21825(5) M.T. Ciceronis De partitione oratoria dialogus : uno fasce, quod aiunt, omnem dicendi doctrinam compl. (Haguenau 1528, J. Setzer). 6) BG/21825(6) Magni Basilei opusculum morale Ad pueros / ex Leonardi Aretini uiri eloquentissimi translatione. (Toledo 1544,J. Ayala). 8) BG/21825(8) 1552, Aphthonii clarissimi rhetoris Progymnasmata / Ioanne Maria Catanaeo interprete; nunc denuo recognita. (Valencia 1552,J. Mey). 9) BG/21825(9) 1559, Iul. Alexandrini medici, Archiatri Caesarei, Paedotrophia: siue de puerorum educatione, liber (Zurich 1559, C. Froschauer).

12 Sobre este impresor, $c f$. Delgado (1996, vol. 2, 753). 
quattuor Evangelia [...] commentarii compositi, \& in luces nunc primum editi. En total, confrontando los datos disponibles en los catálogos, he comprobado la existencia de 48 ediciones de este impresor ${ }^{13}$ o, quizá mejor dicho, de este taller, pues, según menciona Hazañas $(1892,97)$, de Robertis murió en 1550.

El impresor es particularmente conocido por los libros de caballería salidos de sus prensas, aunque no es esta su única actividad. Para la mayor parte de impresos emplea una tipografía gótica característica, común en estos decenios en Sevilla para las obras de caballería, y portada impresa con tacos xilográficos en tinta roja y negra. Todos los impresos del taller reproducen obras en lengua castellana a excepción de tres ediciones en latín, que casualmente son las dos citadas antes -primera y la última del taller- y la de Cicerón de la que me estoy ocupando. Es chocante que, dada la aversión de FCS hacia las novelas de caballería (Sanchís 2012, 79), encargara a este taller la impresión de su edición.

Es posible que parte de los trabajos del taller estuvieran relacionados con la Universidad de Osuna, aunque la edición de la que estoy tratando es de una etapa anterior, pues esta universidad se fundó en 1548 por bula del papa Pablo III.

Entre los libros impresos por de Robertis se pueden citar, además, varios tratados médicos. La única obra de autor clásico que corrió en tinta de molde en latín es este Cicerón, de acuerdo con el corpus de ediciones que he podido constatar, si bien también publicó un Asno de oro en castellano en $1546^{14}$. Un dato de interés es el hecho de que este impresor usa la fecha de la Encarnación en varios de sus trabajos, lo cual modificaría unos meses la salida de la obra si se aplicara a la de FCS, pero como no hay expresión del día o del mes en la obra, ni alusión a la Encarnación, no se puede saber de forma más precisa la fecha exacta de publicación.

Por otra parte, el taller imprimió otro trabajo de FCS el mismo año del Pro Archia, en 1544, la Introducion para ser sabio de Juan Luis Vives ${ }^{15}$, de la cual FCS preparó una nueva edición aumentada dos años más tarde en los talleres complutenses de Juan de Brocar junto con otras obras ${ }^{16}$. La edición de Dominico de Robertis de la Introducion tiene fecha del 5 de enero de 1544, por lo que con toda probabilidad es anterior a la del Pro Archia, en cuyo colofón y portada no hay mención a la fecha más precisa que 1544 .

En la obra de Juan Luis Vives emplea los tipos góticos habituales de su taller, así como portada a dos tintas, roja y negra, también habitual en otros trabajos de sus prensas ${ }^{17}$. Entre los tipos empleados por de Robertis hay muestras en las ediciones conservadas de tipografías góticas, como ya he señalado, así como numerosos tacos xilográficos, en particular en las portadas. Sin embargo, las tipografías itálicas y romanas de varios tamaños, así como la marca del impresor de la portada solo las he podido constatar en esta edición de Cicerón.

De todo lo anterior se puede concluir que este impreso es una rareza entre los trabajos de este taller desde varios puntos de vista.

13 Estos datos son de elaboración propia por cotejo de los catálogos en línea de las principales bibliotecas y repositorios citados en el apartado 5.

Del Asno de Oro, Sevilla, 1546 [USTC 346752 CECLE0275].

Introducion para ser sabio compuesta en latin, Sevilla 1544. [USTC 342504].

Obras, Alcalá de Henares, 1546. [USTC 335632].

El ejemplar consultado es el de signatura R/6243 de la BNE de Madrid. 


\subsection{El editor Francisco Cervantes Salazar}

Francisco Cervantes (de) Salazar (1518-1575) ${ }^{18}$, ha sido objeto de diversos estudios y obras ${ }^{19}$. Es un humanista nacido y formado primero en Toledo por Alejo de Venegas, cuya figura ha estudiado Adeva (1987), que luego completó su formación en Salamanca y más adelante en Flandes, bajo el magisterio de Juan Luis Vives. Tras su periodo de formación el humanista trabajó en Sevilla, quizá en Osuna, y por último en México, etapa que le proporcionó buena parte de su fama. También añado que se ha postulado como autor del Lazarillo en varios trabajos relativamente recientes ${ }^{20}$, aunque más tarde esta hipótesis parece haber perdido consistencia. En el ámbito del humanismo FCS es autor de la primera biografía de Vives, como señala Calero $(1996,53-64)^{21}$, así como de varios comentarios a la obra del humanista valenciano. Es autor, asimismo, de tres diálogos latinos y de varias cartas introductorias en latín en su época mexicana, entre otras obras de distinta índole ${ }^{22}$.

El estudioso toledano se marchó a Nueva España, esto es, México, donde llegó a ser catedrático de retórica y rector de la nueva Universidad allí fundada. Es por este periodo por el que es más conocido el humanista y, en especial, por su Crónica de la Nueva España, en cuya redacción trabajó por última vez en 1566 (Sanchís 2012, 256).

Sanchís $(2012,509-512)$ asigna al humanista 12 obras con diversas ediciones, entre las cuales no figura esta de la que trata el presente artículo, que comienzan en 1542 y terminan en 1570. Además, se han localizado un buen número de documentos manuscritos. La obra que le ha dado más fama, La Crónica de la Nueva España, permaneció inédita hasta 1914, fecha en la que el único manuscrito conservado fue descubierto en la BNE (Paso 1914) ${ }^{23}$.

Tras su formación en Salamanca en la Facultad de Cánones, donde obtuvo el grado de bachiller, y en Flandes, donde continuó su formación con Vives en Brujas, FCS marcha a Sevilla en los últimos años del decenio de 1530 o primeros de la siguiente década como secretario latino del cardenal García de Loaisa. En Sevilla transcurren los siguientes años, periodo durante el cual se publica su Pro Archia. En este tiempo también tuvo encomendadas tareas docentes como él mismo declara en el prólogo del Pro Archia. Tras la muerte del cardenal en 1546 marcha a Alcalá de Henares, donde encarga la impresión de algunas de sus obras a Juan de Brocar, y regresa los últimos años del decenio a Sevilla, en concreto a Osuna, donde posiblemente trabaja como catedrático de retórica hasta su viaje a América hacia 1550. El dato de su trabajo en Osuna no es una cuestión zanjada, pues no figura en los registros de la universidad.

Como corolario se puede considerar que esta edición del Pro Archia es una obra de juventud, pues el editor tendría veintiséis años o quizá treinta cuando se publica y coincide con su etapa como secretario latino del Cardenal García de Loaisa. El año

18 La fecha de nacimiento de FCS ha sido motivo de discusión en diversos estudios con la fluctuación del año de nacimiento entre 1514 y 1518. Esta última es la fecha que defiende Sanchís $(2012,23)$.

19 Además del trabajo de Sanchís (2012), cf. Millares (1958, 19-58).

20 cf. Madrigal (2003, 9-13) y (2003, addenda). Sin embargo, el mismo Madrigal (2008, 137-236) se desdice a sí mismo en un trabajo más reciente. En el mismo sentido Calero (2011).

21 Commentaria in Ludovici Vives. Exercitationes linguae latinae. A Francisco Cervantes de Salazar. Mexico, J. Pablos, 1554, USTC 346498.

22 Sobre esta obra, $c f$. García Icazbalceta (1875).

23 Es el ms. 2011 de la Biblioteca Nacional de España de mediados del s. XVI. 
de la edición encaja asimismo con el de su primera traducción de Vives, publicada también por los mismos talleres.

En efecto, en su periodo Sevillano, durante el cual probablemente compuso y publicó esta edición, FCS pudo haber formado una biblioteca tras su paso por Toledo, Salamanca y Flandes, pero también debió de disponer de los libros que pudiera tener a su alcance en Sevilla al amparo del Cardenal García de Loaisa. Según argumenta Moreno Gallego (2006, 295), en la Sevilla de este tiempo era común el comercio de libros desde Flandes, en particular de impresores como Nucius o Steelsius.

Desconozco si trasladó algún ejemplar de su edición a América y si en su etapa mexicana lo pudo usar en su labor como catedrático de retórica, pues no he encontrado ninguna huella de su trabajo sobre el Pro Archia en esta época.

\section{El texto y comentario}

Dadas las circunstancias de FCS y las manifestaciones que hace en el título y prólogo de la edición y los nombres que cita en su comentario, parece lógico pensar que dispuso de una o varias ediciones del discurso con o sin comentario que le sirvieron de modelo. Conviene indagar los trabajos de los eruditos que nombra y el entorno próximo a la actividad del editor.

\subsection{Las ediciones del Pro Archia anteriores al trabajo de Cervantes Salazar.}

Las primeras ediciones de los discursos publicadas en Italia, como la princeps de Schweynheym y Pannartz (Roma 1471, [USTC 995944]) o las ediciones de F. Beroaldo (Venezia 1506, [USTC 822073]) y la primera Aldina (Venezia 1519, [USTC 822103]) no incluyeron comentarios, pese a que el texto de los discursos, en particular el del Pro Archia, fue objeto de interés y de trabajos desde los hallazgos de Petrarca ${ }^{24}$.

Con relación al texto del Pro Archia, son muchas las ediciones, con y sin comentarios, que se producen antes de esta hispalense. Es relevante destacar que son muy frecuentes en el ámbito germánico, en particular, las ediciones exentas del Pro Archia. Se suceden entre 1484 en Bamberg y 1521 en Leipzig 6 ediciones de este texto, probablemente de uso académico. En los años posteriores de este decenio y del siguiente, varios de los humanistas más notables del momento de esta misma zona realizan nuevos trabajos con este texto. Se edita de nuevo en Estrasburgo en 1524 a cargo de Philippus Melanchthon (Philipp Schwartzerd, 1497-1560). Cinco años después, en 1529 en Colonia, se publica otra a cargo de Bartholomaeus Latomus (Barthélemy Masson 1485-1566) a la que acompaña un breve comentario. Al año siguiente ven la luz sendas nuevas ediciones en París con comentario a cargo de de Franciscus Silvius ${ }^{25}$ (François Dubois, $f$ l. 1515-1535), por una parte, y Martinus

\footnotetext{
Cf. De Kreyser (2013) y De Kreyser - Deneire (2013).

25 La transcripción de este nombre usada por el autor es Syluius, sin embargo FCS prefiere la forma Siluius. El nombre de este humanista lo he normalizado con la forma Silvius. Se trata de Franciscus Silvius Ambianus o François Dubois d'Amiens, profesor de retórica en el Colegio de Tournai en París. Fue comentarista de la obra de Cicerón y de otros autores clásicos. La primera edición de la que hay constancia es el Grifo de Ausonio con comentario (Paris 1516, J. Badius [USTC 181776]). F. Dubois publicó con comentarios un buen número de discursos de Cicerón junto con algunas otras obras ciceronianas Su Pro Archia con comentario es de 1530 (Paris,
} 
Bolerus (Martin Boler Brettanus, $f$. 1526-1562) ${ }^{26}$, por otra. Los años sucesivos continúan en este ámbito del occidente germánico, Países Bajos y París diversas nuevas ediciones de los cuatro comentarios mencionados. Por otra parte, el año de 1534 se imprime en Basilea la edición completa en cuatro tomos de las obras conocidas de Cicerón en las prensas de Johannes Herwagen el Joven. El tercer tomo de esta obra contiene el Pro Archia y la edición está acompañada por un volumen con variae lectiones. Esta obra basiliense se convirtió pronto en una de las vulgatas de los discursos de Cicerón. El número de ediciones con comentarios publicadas en el norte de Europa al discurso de Cicerón contrasta con los comentarios impresos en este periodo de procedencia italiana ${ }^{27}$.

Así pues, como puede verse con detalle en el apéndice 6.7, en los años 1529 y 1530 vieron la luz en un área que comprende París, Amberes, Lovaina y Colonia sendos comentarios al Pro Archia de cuatro importantes estudiosos: Melanchthon, Latomus, Silvius y Bolerus. Estos trabajos tuvieron una buena acogida de inmediato, ya que fueron editados de nuevo en los decenios sucesivos un buen número de veces, incluso en $1539^{28}$ vio la luz una edición conjunta con los cuatro comentarios reunidos en el mismo volumen por M. Vascosan reeditada varias veces en años sucesivos ${ }^{29}$. La edición conjunta de los cuatro comentarios, además de corregir erratas, modernizar las grafías y la puntuación en los comentarios y paratextos, actualiza el texto de Cicerón tomando variantes presentes en la edición de Hervagius, que posiblemente empleó como referencia para corregir el texto de Cicerón. Este mismo año de 1540 comienza la impresión una nueva edición aldina con nuevas enmiendas (USTC 822228).

Ya después del trabajo de FCS, salió de las prensas aldinas en 1547 (USTC 803239) una nueva edición completa de los discursos acompañados por los comentarios disponibles hasta entonces, que en el caso del Pro Archia son los 4 mencionados. Este dato confirma la impresión de que la edición Sevillana no tuvo repercusión en los sucesivos impresos fuera de España.

A la vista del peso de los eruditos que editaron el Pro Archia en los primeros decenios del Quinientos, se puede afirmar que se trata sin duda de un texto bien difundido y estudiado en la época en que FCS lo edita y los trabajos de estos sabios es probable que estuvieran al alcance del toledano durante su estancia en Flandes, donde estuvo en contacto con Vives y, sin lugar a dudas, con otros humanistas y los trabajos de la época. Es muy probable, en mi opinión, que estuviera al tanto de las

J. Badius [USTC 184965]). También editó un comentario a los Epigramas de Marcial (Paris, J. Kerver [USTC 185736]). Sus fechas de nacimiento y muerte no son conocidas, pero estuvo activo en las décadas de 1510 a 1540. Es hermano de Jacques Dubois (1478-1555), médico y autor de la primera gramática francesa, cuyo hijo es el homónimo François Dubois (1529-1584), conocido pintor.

26 Con respecto a los cuatro humanistas, especialmente sobre los tres primeros, existe una abundante literatura, pero no así sobre el último, Martinus Bolerus Brettanus. Su actividad se desarrolló entre 1526 y 1563 . Conocido sobre todo por sus traducciones latinas de Luciano de Samósata.

27 En Italia desde la aparición de la edición aldina se suceden otras como las de los Giunta, pero no se imprimen nuevos comentarios de procedencia italiana. Incluso se publican los comentarios habituales de Silvius, Melanchthon, Latomus, etc. v.g. Venezia 1538, Nicolini USTC 827800.

28 El ejemplar que he manejado de esta obra es el de la edición de 1541 que guarda la ÖNB, sig. 45.T.35. No he tenido la oportunidad de manejar ejemplares de las ediciones anteriores, por lo cual pongo las afirmaciones hechas sobre Boler en cautela por las posibles discrepancias de esta edición y las anteriores de 1530 y 1537.

29 Pro Aulo Licinio Archia poeta oratio commentariis, annotatiunculis illustrata, Paris, Vascosan, 1539 [USTC 186173], Id. 1541 [No consta en USTC]. [USTC 140271], id, 1547 id. Richard 1550 [USTC 203971], Fezendat 1550 [USTC 203972] 
novedades editoriales que se producían o llegaban a Flandes en este periodo. Además el editor reconoce ya en la portada y cita en su comentario a estudiosos, entre los cuales Silvius es mencionado expresamente 2 veces $^{30}$.

Inaugura, así pues, el teólogo y humanista alemán Melanchthon una serie de ediciones comentadas del Pro Archia, de la que la edición de FCS es un peldaño más y de la cual posiblemente se sirve como fuente textual, tanto para el texto de Cicerón como para los comentarios y paratextos.

\subsection{Las menciones a otros humanistas de Cervantes Salazar en su comentario y paratextos}

Antes de analizar los paratextos y el texto de esta edición hispalense conviene detenerse en el hecho de que esta obra ve la luz tras el paso de FCS por Flandes en la segunda mitad de la década de 1530 .

Para esclarecer qué clase de texto es el editado por FCS y, en particular, la filiación textual de la edición y comentario, he partido del estudio de las ediciones más relevantes del Pro Archia de los años anteriores a la publicación del trabajo de FCS. El propio editor cita algunos de los autores cultivados - docti viri- de los que se ha servido en sus comentarios. Estos son Silvius, autor de un importante grupo de ediciones con comentarios a Cicerón ${ }^{31}$, entre ellas su edición y comentario del Pro Archia. Además, Fenestella $^{32}$, Alexander ${ }^{33}$, Nizolius ${ }^{34}$, si bien no hace ninguna afirmación explícita sobre el modelo de su texto ciceroniano. En el comentario se refiere a Silvius en varias ocasiones. Ninguno de los otros eruditos citados es autor de ediciones de Cicerón, si bien Nizolius lo es del Thesaurus Ciceronianus que cita FCS en el comentario.

En los otros paratextos también se citan algunos nombres propios. El primer paratexto es una dedicatoria al lector anónimo (h. [a2r]). Esto es algo poco común, pues no parece que FCS fuera en esta época persona acaudalada como para hacerse cargo de las expensas de la impresión, más aún en un momento en el cual está al servicio del Cardenal García de Loaisa. En su contenido se pueden indagar las causas y la finalidad que le llevaron a componer el comentario y editarlo junto con el texto de Cicerón y ver el contexto en el cual se fraguó este trabajo ${ }^{35}$. En primer lugar, FCS argumenta que, ha explicado la breve retórica de Joaquín, pues una más amplia no le estaba permitido por falta de tiempo. Sin embargo, dice que muchos le pidieron que enseñara en algún discurso lo que había transmitido en los preceptos, puesto que es difícil usar los preceptos sin ejemplos. Añade que, dada la falta de tiempo y para evitar gastos, ha decidido editar este discurso para que sirva para practicar los preceptos de la retórica añadiendo comentarios y aclaraciones de otros y suyas.

Desde 1530 se había difundido mediante varias ediciones una Rhetorica de Joachimus Fortius Ringelbergius ${ }^{36}$, humanista flamenco de nombre original Joachim

\footnotetext{
Cf. hh. [a6r] y b1r.

Sobre Silvius, $c f$. n. 27.

Se trata de Andrea Domenico Fiocchi, conocido con el nombre latino de Lucius Fenestella, nacido en Florencia en fecha desconocida y muerto en Roma, en 1452. Sobre este autor $c f$, Pignatti (1997).

Citado en ff. a5r y [a8r] Alexandre de Villadei o Alexandre de Villedieu (ca. 1175-1240).

cf. f. a4r, Nizolius o Mario Nizoli de Brescia (1498-1576). Sobre este autor $c f$. Palumbo (2013).

Para una visión más completa de los paratextos, $c f$. Apéndices 6.3-6.6.

Rhetorica, París 1530. [USTC 185069]
} 
Sterck van Ringelberg, a la cual es muy probable que FCS tuviera acceso en los años en Flandes y quizá también después en Sevilla ${ }^{37}$.

Dan fe de que esta Rhetorica tuvo difusión en la Península los ejemplares conservados de la misma y la existencia de una nueva edición publicada en Coimbra en $1550^{38}$

La edición que he podido manejar de esta $\mathrm{obra}^{39} \mathrm{es,} \mathrm{como} \mathrm{afirma} \mathrm{el} \mathrm{propio} \mathrm{FCS,}$ un trabajo breve. Se trata de un impreso en octavo de 40 páginas que hace un rápido recorrido por los preceptos de la retórica que eran usuales en este periodo. De un primer análisis se comprueba que se trata de un manual del estilo de las traducciones de Aftonio, muy populares en la época. Los ejemplos que propone Sterck (Fortius) para ilustrar los preceptos retóricos están tomados de los grandes poetas augústeos, muy en particular de Ovidio y de Virgilio, aunque también recurre alguna vez a otros como Homero.

No obstante, no se constata ninguna mención más de esa Retórica de Joaquín, a la que alude FCS, de modo que no puede afirmarse más que con cautela que esta fuera la de Joachim Sterck. En todo caso, fuera cual fuere el tratado de retórica mencionado, esto no afecta a la filiación del texto de la edición, ya que acaso había servido como guía de los comentarios al texto.

\subsection{Los paratextos iniciales, argumentum y dispositio y sus posibles modelos}

En los dos siguientes paratextos de la edición sevillana, que preceden al Pro Archia, se puede extraer una cierta información de los posibles modelos textuales, si se consigue saber quiénes pudieron ser los humanistas a los que alude en el título.

Recordemos que se indica en el título que el texto está acompañado por escolios de hombres doctos y aclaraciones del propio FCS: "M.T.C. ORA|TIO PRO ARCHIA POETA DOCTORVM VIRORVM SCHOLIIS, ADIECTIS QVIBVSDAM FRANCISCI CERVAN|TIS SANAZARI ELVCIDATIONIBVS ILLVSTRATA". Sin embargo, qué parte pertenece a cada cual o quiénes son esos hombres doctos no es una cuestión de fácil solución. No obstante, de acuerdo con el título, parece deducirse por la manera de redactarlo que los paratextos que preceden al discurso, el argumentum y la dispositio son de esos docti viri que cita el título y, por el contrario, los comentarios, que parece llamar elucidationes, de la columna exterior son del propio FCS.

Para tener una idea más clara conviene analizar el contenido y presentación de los tres paratextos iniciales. Del titulillo del Argumentum se deduce que es obra del propio FCS: "FRANCISCI | CERVANTIS SANAZARI | IN M. T. C. ORATIONEM| PRO ARCHIA POE-|TA ARGVMEN-|TVM.”, sin embargo, en la segunda mitad del mismo, en h. a.3r, 1. 5-8, añade: "Volui scriptum a doctis antea argumentum meis verbis vestire ut tamquam novum placeret. addidi etiam nonnulla, quae ipsi volentes

37 Con el título de Dialectica Rhetorica. Liber de formis dicendi. Opusculum de periodis. Quaedam de accentibus, publica primero en 1530 , luego en $1534,1536,1537,1538,1539,1540,1542$ y 11543 . Además de estas ediciones, todas ellas publicadas en Paris; hay también una edición de 1542 publicada en Lyon. Después de la edición de FCS este trabajo continuó reeditándose al menos otras 13 veces, no solo en Francia, sino también en Coimbra 1550 [USTC 343414] y en Roma 1552 [USTC 852630].

38 Sobre los ejemplares conservados en Portugal y, en especial sobre la edición de Coimbra, $c f$. Pereira (2004, 201-213).

39 Se trata de la edición de Lion 1550, Sebastianus Gryphius [USTC 123064]. El ejemplar consultado es el de signatura R/27621(3) de la BNE de Madrid. 
forsan reliquerunt ..."40, de donde se sigue que la parte final del mismo, las últimas 7 líneas del Argumentum, son propias, pero las primeras 26 son ajenas, tomadas de esos viri docti.

El tercer paratexto tiene una atribución más clara, pues el titulillo que precede a la Dispositio dice así: "M.C.T. ORATIONIS PRO ARCHIA | POETA DISPOSITIO EX | PROBATISSIMIS AV-|thoribus per eiusdem breviter $\mid$ excerpta"41. De estas declaraciones del autor se deduce que esta introducción no es obra original suya, aunque la ha abreviado. Más adelante y en los apéndices 6.3-6.6 volveré sobre estos paratextos.

En primer lugar, he estudiado el argumentum que también incluyen en sus ediciones Latomus y Silvius. La edición de Melanchton, en cambio, contiene una amplia Dispositio de 9 pp. (hh. A2r-A6v) y una Paraphrasis aún más extensa. Finalmente, la obra de Bolerus tiene un paratexto inicial que titula Scholia de una índole distinta en donde no se refiere a las circunstancias del discurso y de su protagonista (ff. 5v$7 \mathrm{v})$. Este conjunto es reeditado por Vascosan en 1539 con algunas modificaciones menores y creo que puede ser esta la edición empleada por FCS.

Las divergencias con el argumentum de Latomus son más significativas, tanto en el orden como en el contenido y más aún con los scholia de Bolerus. Sin embargo, el argumentum de Silvius y el de FCS tienen una coincidencia notable en los elementos que se introducen, en el vocabulario y en el orden en que se citan, aunque no hay una correspondencia verbatim y en el de FCS hay una sección que Silvius no recoge: referencias a otros Arquias distintos del poeta Aulo Licinio Arquias. Del análisis de este paratexto en su conjunto se puede deducir que el de Silvius pudo servir como fuente, pero no fue la única ni se limitó a reproducirla, si bien parece que le inspiró, como puede deducirse de las palabras del propio FCS que he reproducido más arriba.

En el caso de la Dispositio, el segundo paratexto de introducción al discurso, se produce una situación parecida, aunque en este caso he detectado la copia literal de una buena parte del paratexto homólogo de la edición de Melanchthon de $1533^{42}$, como se ve señalado en negrita en los apéndices. En este caso, el paratexto del humanista alemán es mucho más extenso y FCS se limita casi por completo a escoger algunos pasajes o frases que considera más importantes y reproducirlos, sea adaptados, sea copiados literalmente, de modo que son muchas las frases y palabras que coinciden literalmente con las de la edición de Melanchthon.

Estos dos elementos paratextuales son suficientes para demostrar la dependencia textual de la edición de Melanchthon y también de la de Silvius, pues se demuestra que FCS las conocía y las integró parcialmente en su aparato de anotaciones al Pro Archia. El caso de la Latomus y de Bolerus no queda acreditado ${ }^{43}$.

\footnotetext{
40 "He querido revestir el argumento escrito antes por sabios con mis palabras, para que guste como uno nuevo. He añadido también algunas cosas que esos mismos quizá se dejaron a propósito”. Traducción propia.

41 "Disposición del discurso de M. T. C. en defensa del poeta Arquias de autores excelentes resumida brevemente por el mismo". Traducción propia.

42 El ejemplar que he consultado es el de la BSB de Múnich, signatura A. lat. B. 261.

43 Las 4 ediciones tuvieron una amplia repercusión y difusión a juzgar por las numerosas veces que fueron reeditadas, $c f$. Apéndices.
} 


\subsection{El texto de Cicerón}

La parte más substancial de la edición es el texto del Pro Archia. Para el análisis de las variantes textuales he seguido el método propuesto por Moreno Hernández ${ }^{44}$. El texto establecido por FCS coincide en buena medida con el texto escogido por las principales ediciones críticas modernas y resuelve los loci critici más relevantes de forma semejante ${ }^{45}$. Puesto que el comentario de FCS toma partes significativas de las ediciones mencionadas, parece conveniente colacionar el texto con las de aquellas, si bien las variantes pueden partir obviamente de testimonios más antiguos de la transmisión y de hecho la mayor parte están presentes en la transmisión manuscrita.

Después de la colación del texto del Pro Archia de FCS y los antecesores, aparte de las variantes gráficas de resolución de diptongos, uso de u/v, i/j, abreviaturas, etc., se documentan 52 variantes con respecto a los precedentes de Latomus, Silvius, Melanchton y Vascosan / Hervagius ${ }^{46}$, de las cuales solo seis son exclusivas de FCS. De estas variantes privativas cuatro son distintos compuestos verbales, e.g., obhorruisse (a4r, 10) frente abhorruisse, tres parecen erratas tipográficas, e.g., vinebat por viuebat-este ejemplo es el más claro de error tipográfico-; notu frente a motu y multi en vez de multis. Algunas de estas variantes podrían ser obra del propio FCS, pero no se sabe si surgieron ope ingenii o codicum / editionum.

El conjunto de variantes del texto es de cierta entidad, pues hay variantes léxicas, de orden, omisiones, etc. y el texto ciceroniano presenta variantes separativas significativas del texto de Melanchthon (32) y conjuntivas con el de Latomus, Silvius y Vascosan / Hervagius. Dentro de esta última rama las variantes separativas con Latomus son evidentes, de modo que se puede sostener, en mi opinión, que en el texto del Pro Archia FCS siguió la edición de Silvius y la de Vascosan / Hervagius y no la Latomus y menos aún la de Melanchthon, aunque empleó estas ediciones para sus partextos ${ }^{47}$.

En las variantes que se producen entre FCS, Silvius y Vascosan / Hervagius, el toledano sigue en más ocasiones a Vascosan / Hervagius en los casos más significativos, pero no siempre, y en algunos casos se decanta por las variantes de Silvius. El conjunto de variantes exclusivas de FCS es de escasa entidad. No hay ninguna omisión o trasposición. Además, estas variantes privativas no están registradas entre las variantes de los aparatos críticos de Clark (1984 [=1910]), o Gaffiot (1966 [=1938]), o en el trabajo de De Keyser (2013). En todo caso, demuestran una labor filológica del humanista que no se limita a reproducir y seleccionar de los anteriores.

44 Este método se deduce de los trabajos de Moreno (2004, 2005, 2005b, 2006, 2008, 2008b, 2009, 2010) citados en la bibliografía.

45 He consultado las ediciones de Clark (1910) y Gaffiot (1938). En ambas se consideran los codd. G, Bruxellensis 5352 (s. XI) y E, Erfurtensis (ca. 1158), y V, Pal. lat. 1525 (1476), los más fiables. En la edición de Gaffiot se reproduce un artículo suyo anterior con un estudio detallado de los principales loci critici, Gaffiot (1929, 348365 ) Todos estos estudios han sido revisados y en buena medida refutados por Keyser (2013) y Kreyser, Deniere (2015), quienes han añadido un subarquetipo $\pi$ que contiene la transcripción y correcciones de Petrarca al ms. que encontró en Lieja. El mss. a Firenze, Biblioteca Medicea Laurenziana, Plut. 23 sin. 3 (s. XIV) se considera el primer representante de esta tradición.

46 Nombres latinizados que se usan habitualmente en los escritos de la época de Barthèlemy Masson (1485-1566), François Dubois ( $f$.1520-1540), Johann Herwagen el Joven (1497-1559) respectivamente. Sobre estos humanistas es muy amplia la bibliografía, para una visión sinóptica, $c f$. Deutscher (2003,186-187).

47 Para ver el listado total de variantes, $c f$. Apéndice 6.2. 
De todo lo anterior se puede deducir un stemma editionum como sigue ${ }^{48}$ :

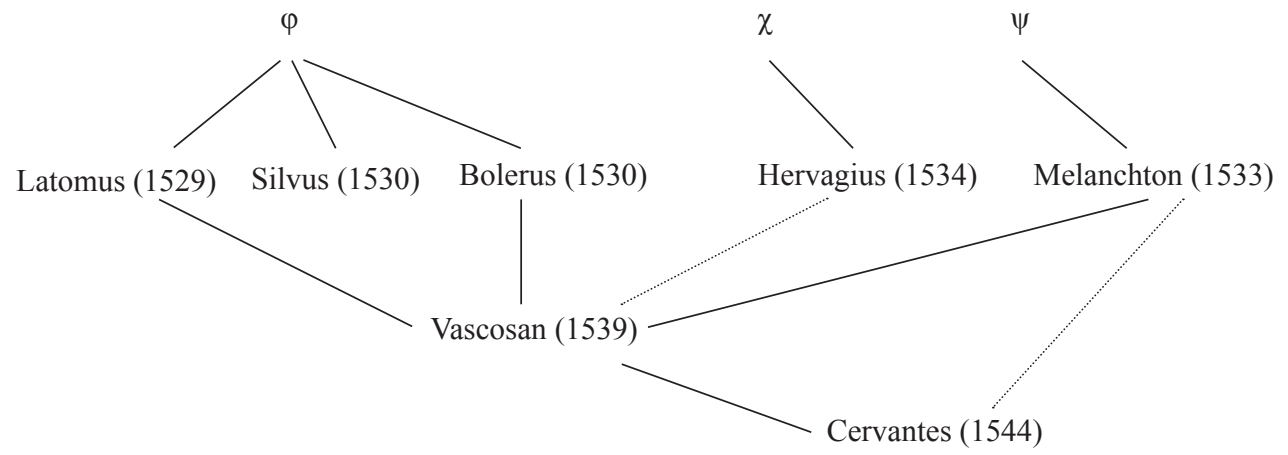

\subsection{El comentario}

Con respecto al comentario, en cambio, no he detectado una dependencia literal de ninguno de los modelos, aunque el propio FCS alude explícitamente a varias de sus fuentes, en particular, Silvius ${ }^{49}$, Fenestella $^{50}$, Alexander ${ }^{51}$, Nizolius $^{52}$. Esta última puede servir como término post quem para la redacción de la obra de FCS, ya que la edición de Nizoli es de 1535. Pienso que el terminus post quem de la elaboración de la obra de FCS se puede retrasar aún más, hasta 1539, si, como indican las pruebas, usó la edición impresa por Vascosan. No obstante, los comentarios son de una entidad y profusión mucho menores en FCS que en las ediciones precedentes, pues a menudo son un simple sinónimo, en cambio en Silvius, en Bolerus y en Melanchthon son más profundos y a menudo se acompañan con citas prolijas de autoridades y obras de clásicos latinos y griegos, frente a pocos casos en FCS $^{53}$.

El comentario es sobre todo de índole retórica escolar, con alusiones a las distintas partes del discurso, figuras, etc, pero también de realia con explicaciones a muchas de las instituciones romanas que salen a colación en el Pro Archia, a cierto léxico específico, etc.

Por otro lado, los pasajes comentados son, casi sin excepción, también tratados en las ediciones de comentarios anteriores, de manera que en este sentido tampoco cabe destacar una gran originalidad, aunque, insisto en esto también, no he detectado copia literal de los comentarios inmediatamente anteriores. En el comentario, generalmente de realia, cita FCS alguna de sus fuentes o remite a explicaciones más amplias de otros autores coetáneos; entre ellas ya se ha citado a Nizolius o Silvius,

48 Con $\varphi, \chi, \psi$ solo pretendo representar tres ramas diferentes de la transmisión del texto. Con las líneas discontinuas pretendo mostrar contaminatio. En el caso de Melanchton se aprecia en los paratextos con más claridad.

49 Citado en h. [a6r] y b1r.

50 Citado en hh. a5r y [a8r]. Se trata de la obra de Fenestella, De magistratibus sacerdotiisq[ue] Romanorum libellus, M. Landsberg, Leipzig 1509 impreso (USTC 673631) y reeditado varias veces en los siguientes decenios.

51 Citado en ff. a5r y [a8r]. Aunque son varios los posibles candidatos me inclino por el Doctrinale de Alexander de Villadei, que cuenta con muchas ediciones en este periodo.

52 cf. f. a4r, Nizolius o Mario Nizoli de Brescia, quien publicó en 1535 Observationes in M. Tullium Ciceronem, Brixiae. Esta obra contiene un abultado diccionario ciceroniano.

53 Son muy abundantes los comentarios a Pro Archia en particular, y a la obra oratoria de Cicerón, en general publicados en los años anteriores a este de FCS y no he tenido la posibilidad de consultarlos todos. 
pero también -y con más frecuencia- menciona obras y autores antiguos como Macrobio (h. [a4v]), Salustio (h. [a6r]), Livio (h. [a6v]), Servio (h. [a7r]), Virgilio (h. [a7r]), Aulo Gelio (h. [b3v]), Eusebio (h. [b3v]), Plutarco (h. [b4v]), Silio (h. [b5r]), Estrabón (f. [b5v]), o el propio Cicerón en otras de sus obras ${ }^{54}$. De todo ello se sigue que su comentario, pese a no añadir temas originales sustanciosos, denota una labor propia sobre el texto y cumple el propósito que FCS apunta en el prólogo: ilustrar en un discurso los preceptos de la retórica.

\section{Conclusiones}

La edición del Pro Archia con comentario impresa en Sevilla en 1544 representa una novedad editorial en el contexto hispano, toda vez que constituye la primera edición de este texto ciceroniano salida de talleres ibéricos, de la cual se conserva un solo ejemplar. Se han identificado en buena medida los modelos inmediatos de la edición y la manera variada en que se integran en la edición y comentario de FCS. Del análisis de la edición se puede concluir que la edición del Pro Archia de FCS no introduce grandes novedades ni en el texto, ni en los comentarios e introducción al mismo. Aunque no se puede descartar que pudiera haber dispuesto de ediciones o manuscritos anteriores, la colación proporciona indicios claros de que no procede de un modelo único, sino que se basa en el manejo de varias ediciones inmediatamente anteriores y muy en particular de las de Vascosan (Paris 1539), quien edita de nuevo los comentarios de Silvius, Bolerus, Latomus y Melanchton, pero corrige el texto de Cicerón siguiendo de cerca la edición de Hervagius. En los paratextos iniciales sigue a la edición de Melanchthon, que se publicó por primera vez en Estrasburgo en 1524 y fue reeditada en varias ocasiones, así como la de Silvius (París 1530), que también se ha comprobado para el texto de Cicerón y comentario. Tuvo asimismo acceso a algunas obras destacadas sobre Cicerón y de algunos textos clásicos, según se deduce de sus citas y menciones.

Esta manera de proceder denota un cierto trabajo filológico sobre el texto, pues no se limita a reproducir el material del que dispone, sino que lo analiza y selecciona en cierta medida y, a la vista de las ediciones críticas actuales, con cierto criterio en la elección de variantes.

Se trata además de una obra pionera en España que demuestra altura intelectual de FCS, el cual, aunque se sirva de fuentes anteriores, demuestra un trabajo sobre el texto y un conocimiento de este, de Cicerón y de la retórica.

El editor, en un acto de honradez, reconoce que ha empleado el trabajo de otros humanistas, aunque no los cite a todos por su nombre. Quizá la ausencia del nombre de Melanchthon esté motivada por una cuestión de censura que hubiera podido poner en riesgo la publicación de su obra por tratarse de un reconocido luterano.

Desconozco el uso y difusión que pudo tener este trabajo y el único dato que puedo afirmar es que el ejemplar conservado se empleó en la universidad de Salamanca del siglo XVII. En todo caso, la publicación solo unos años después de los discursos completos con los comentarios de esta época en las prensas aldinas debió limitar una posible repercusión de este impreso.

${ }^{54}$ cf. v. g. la referencia al De oratore en hh. [a5r-v], Pro Murena b2r, Re Publica b2r, Tusculanas [b6v]. 
No tengo noticias de que esta obra se volviera a editar o sirviera de modelo para nuevas ediciones, pues la edición también con comentario de Francisco Fernández de Córdoba impresa en Valladolid en 1546 no muestra relación con el impreso de $\mathrm{FCS}^{55}$.

\section{Bibliografía}

\subsection{Referencias}

Adeva Martín, I., (1987), El Maestro Alejo Venegas de Busto: su vida y sus obras, Toledo. Altmann, W.H.F. (ed.), (2015), Brill's Companion to the Reception of Cicero, Leiden - Boston.

Arcos Pereira, T., (2015), «Los primeros niveles de la enseñanza de la retórica: los progymnasmata», en J. Ma Maestre Maestre, S. I. Ramos Maldonado, M. A. Díaz Gito, M ${ }^{\mathrm{a}}$ V. Pérez Custodio, B. Pozuelo Calero, A. Serrano Cueto (coords.), Humanismo y pervivencia del mundo clásico. V: homenaje al profesor Juan Gil, vol. 3, 1163-1190.

-, (2017), «El ejemplar salmantino de los Aphthonii clarissimi rhetoris Progymnasmata Ioanne Maria Catanaeo interprete, de Juan Lorenzo Palmireno (BG/221825): La recuperación de una obra perdida», Cuadernos de Filología. clásica. Estudios lattinos 37.1, 105-118.

Calero Calero, F., (1996), «Francisco Cervantes Salazar, autor de la primera biografía de Luis Vives», Epos 12, 53-64.

—, (2011), «Los Coloquios de Palatino y Pinciano y la palinodia de José Luis Madrigal», Espéculo: Revista de Estudios Literarios 47, sin paginación, url: https://webs.ucm.es/info/ especulo/numero47/palatino.html.

Castillejo Benavente, A., (2019), La imprenta en Sevilla en el siglo XVI (1521-1600), Sevilla. Clark, A., (1984 [1910]), Ciceronis Orationes, Oxford.

Clark, D. L., (1952), «Rise and Fall of Progymnasmata in Sixteenth and Seventeenth Century Grammar Schools», Speech Monographs 19.4, 259-263.

Coronel Ramos, M. A., (ed.), (2017), Juan Luis Vives. El humanista y su entorno, Valencia.

Cox, V., Wards J., (2006), The Rhetoric of Cicero in its Medieval and Early Renaissance Commentary Tradition, Leiden.

Graig, C. (2002), «A survey of selected recent work on Cicero's rhetorica and speeches» en May, J. M. (ed.), Brill's Companion to Cicero Oratory and Rhetoric, Leiden-BostonKöln, 503-532.

Delgado Casado, J., (1996), Diccionario de impresores españoles ss. XV-XVII, Madrid, 2 vols.

Deutscher, Th., (ed.), (2003), Contemporaries of Erasmus: A Biographical Register of the Renaissance and Reformation, Toronto.

Enenkel, K., (ed.), (2014), Transformations of the Classics via Early Modern Commentaries, Leiden-Boston.

Gaffiot, F., (1929), «Le texte du Pro Archia», Revue de Philologie 55, 348-365.

55 El único ejemplar de esta edición se conserva en la British Library con signatura C.63.d.27(1). Los datos de lugar y fecha de publicación no aparecen expresamente en el impreso. El título que figura en el catálogo es: Pro A. Licinio Archia poeta oratio explicata scholiis Decii Ferdinandi Friatis Salazari. In quibus preter alia artificium rethorices. [USTC 342837, CECLE0251]. 
—, (1966 [1938]), Cicéron. Discours Tome XII, Paris.

García Icazbalceta, J., (1875), México en 1554. Tres diálogos latinos que Francisco Cervantes Salazar escribió e imprimió en México en dicho año, México.

Hazañas y la Rúa, J., (1892), La imprenta en Sevilla: ensayo de una historia de la tipografía sevillana y noticias de algunos de sus impresores desde la introducción del arte tipográfico en esta ciudad hasta el año 1800, Sevilla, 96-97.

Keyser, J. De, (2013), «The Descendants of Petrarch's Pro Archia», Classical Quarterly 63.1, 292-328 (doi: 10.1017/S0009838812000596).

Keyser, J. De, Deneire, T. (2013), «A New Stemma for Cicero's Pro Archia» Eikasmos 24, 193-208.

López Grigera, L., (1994), La retórica en la España del Siglo de Oro. Teoría y práctica, Salamanca.

Madrigal, J. L., (2003), «Cervantes de Salazar y el Lazarillo: un estudio de atribución», Insula: revista de letras y ciencias humanas, 682, 9-13.

—, (2003b), «Cervantes de Salazar, autor del Lazarillo», Artifara: Revista de lenguas y literaturas ibéricas y latinoamericanas 2, sin paginación, DOI: https://doi.or$\mathrm{g} / 10.13135 / 1594-378 \mathrm{X} / 2399$.

—, (2008), «Notas sobre la autoría del Lazarillo», Lemir 12, 137-236.

Marsh, D., (2011), «Cicero in the Renaissance» en Steel, C. (ed.), The Cambridge Companion to Cicero, Cambridge, 306-317.

McLaughlin, M. (2015), «Petrarch and Cicero: Adulation and Critical Distance», en Altmann, W.H.F. (ed.), Brill's Companion to the Reception of Cicero, Leiden - Boston, 17-38 (DOI: https://doi.org/10.1163/9789004290549_003).

Millares Carlo. A., (1958), Apuntes para un estudio bibliográfico del humanista Francisco Cervantes de Salazar México, Universidad Nacional Autónoma de México.

Moreno Gallego, V., (2006), La recepción hispana de Juan Luis Vives, Valencia.

Moreno Hernández, A., (2004-2005), «La edición de Philippo de Giunta del Bellum Gallicum de César (Florencia 1514)», Epos 20-21, 13-30.

—, (2005), «César, Bellum Gallicum, Parisinus Lat. 5767», Emerita 73 , 217-232.

-, (2005b) «En torno a la filiación del texto del Bellum Gallicum de César en el manuscrito Escurialensis M.III.10», Cuadernos de Filología Clásica. Estudios Latinos 25.1, 5- 25.

-, (2006), «La edición de los Commentarii de César de Venecia, 1511: ¿emendatio original o mera copia?», Epos 22, 21-37.

-, (2008), «En torno a la puntuación en las primeras ediciones postincunables de los Commentarii de César (1504-1513)», en A. Cascón Dorado et alii (eds.), Estudios en Homenaje al Profesor Vicente Picón García, Madrid, Universidad Autónoma de Madrid, 331-351.

—, (2009), «Bases manuscritas de la práctica conjetural de la edición aldina del Bellum Gallicum de César (Venecia 1513)», Emerita 77. 2, 223-245.

—, (2009b), «Precisiones sobre el valor de la puntuación en las ediciones incunables y postincunables de la obra de César», en $\mathrm{M}^{\mathrm{a}} \mathrm{A}$. Almela Lumbreras et alii (coords.), Perfiles de Grecia y Roma, I. Actas del XII Congreso Español de Estudios Clásicos, Madrid, SEEC, 267-274.

-, (coord.) (2010), Julio César: textos, contextos y recepción. De la Roma Clásica al mundo actual, Madrid, UNED.

Paso y Troncoso, F. Del, (ed.), (1914), Cervantes de Salazar, Crónica de Nueva España, vol. I, Madrid. 
Pereira Fernandes B., (2004), «A edição conimbricense da Rhetorica de Joachim Ringelberg», Península 1, 201-213.

Pignatti, F., (1997), s.u. «Fenestella», en Dizionario Biografico degli Italiani, Vol. 48. http:// www.treccani.it/enciclopedia/andrea-fiocchi_\%28Dizionario-Biografico\%29/ [20-012019].

Sanchís Amat, V. M., (2012), Francisco Cervantes de Salazar (1518-1575) y la patria del conocimiento: la soledad del humanista en la ciudad de México, Alicante, Universidad de Alicante, Tesis doctoral.

\subsection{Repertorios}

BECLAR (CICLE, CECLE) = Biblioteca de Ediciones de Clásicos Latinos en el Renacimiento. (http://incunabula.uned.es)

Biblioteca Virtual Miguel de Cervantes = (http://www.cervantesvirtual.com/)

$C C P B E=$ Catálogo Colectivo del Patrimonio Bibliográfico Español () $G W=$ Gesamtkatalog der Wiegendrucke (https://www.gesamtkatalogderwiegendrucke.de/) ISTC = Incunabula Short Title Catalogue (https://data.cerl.org/istc/_search) USTC = Universal Short Title Catalogue (https://www.ustc.ac.uk/) WorldCat $=($ https://www.worldcat.org/)

\subsection{Bibliotecas citadas}

$B L$

$B N E$

$B N F$

$B S B$

$B U$ Salamanca
British Library

Biblioteca Nacional de España

Bibliothèque Nationale de France

Bayerische Staatsbibliothek

Biblioteca General Histórica de la Universidad de Salamanca 
6. Apéndices ${ }^{56}$

\subsection{Imágenes de la edición}

Portada, carta dedicatoria, Argumentum, Dispositio, Colofón.

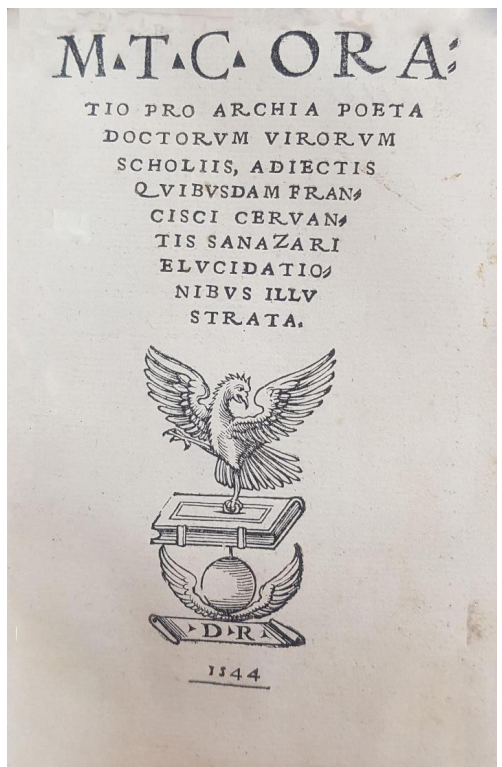

etileneys, $\sigma$ alius epigrămaton $\int$ criptor, $\sigma$ alius qui de agri cultura feripfit, frit $\odot$ A Arcbias preco celeberrimus, qui tres ordine Olimpia las uicit, fint $\approx$ Archias qui Syrach jas in $\mathrm{Si}$ cilia condidit, quorum o:nzism authores $\int u n t$. Pedianus, An tonius, Lufcus, Volaterranus, Suidas, $O$ Polsx. Volui fcris ptum a doct is antea argumentü meis uerbis ueftire, ht tanqu noukm placeret, addidi etiam nönulla, que ipft nolentes for Jan reliqueruat. Cau $\int$ e genus inficiale eft, cut (quia Cicero in laudes Arcbie diuertitur) imixtum eff demonffrattuñ.Stas ths caufe (in quo tota caufa confiffit) conicctural is eft. Q ue ritur enim an сініs fit Archias. Sunt artem ftatus tres, con iecturalis, legitimus, $\sigma$ iuridicialis. quorü queftiones funt, an fit, quidfit, quale fit. Oportet autem ftatus meminifje les Etorem, ut reliqua omnia facile intelligat.

M.T.C. ORATIONIS PRO ARCHIA

POAETA DISPOSITIO EX

PROBATISSINIS AV

thoribus per cundem breniter excerpta. -

RATIO HAEC PRIMVM OMNI, หm, exordio, narratione, confirmatione confutations permixta, $\sigma$ per oratione conftat. Sed quo pacto partes bie tractentur, ut recte difpofita sideatkr oratio, pancis accipe. Locus excordij fumptuseft ex cŏmuni loco, fcilicet ex officio referende gratie: $\sigma$ bac ex propofitione exordism totü nas fcitur.Cicero enim refert fe defere Ardbiant defendere, ut ci

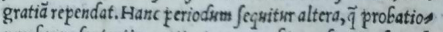

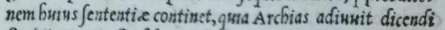
ftudiñ. Tertio cft addita cöclufio, equй enimt cff, ut qui aro * $i$ ij

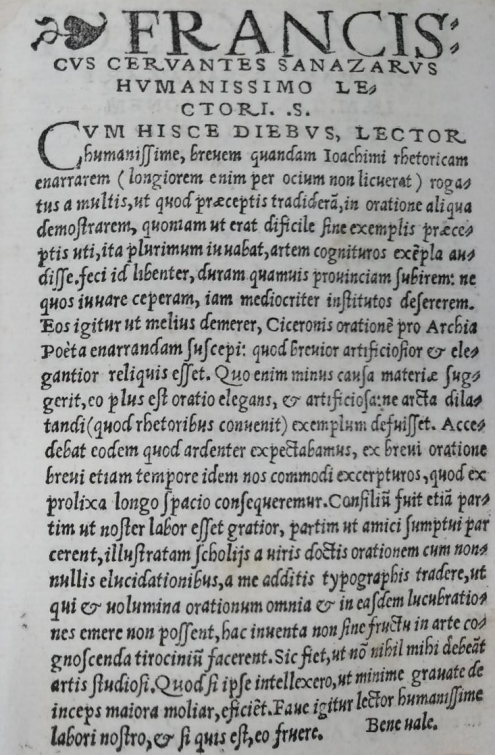

PRO ARCHIA POETA

bunt, nune quidem certecogrtatione quadam, fé'p delector.

Quare cö Serrate Irdices bomis

nê, pudore co, què anicorü ftu $q$ Quare conferuace) epidij̣s uidet is cốprobari, tü digni logurfeu conclufio oratiotate, tum ctiä uenuftate:ingenio nis côft âs breui argumêto autêt tanto, quantü ió conuenit rủ repetitió e \&C affectubus

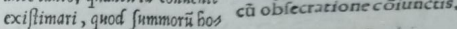
minü ingenijs expetitü efJe rideat is : caufa neтo cinfmodi, que beneficio legis, ahtoritate municipij, teftimonio Lucklli, tabslis Mctelli cöprobetนr.Q นе сй ita

fint, petimus à robis Irdices, $f$ q Quæ cum ita fint), oblequa nõ modo brumana, nerüetiă cratio.

dirina in tantis negotijs cơmen

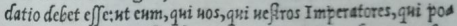
puli $R$ omani res geftas \emper ornauit: qui etiam bis recentibus

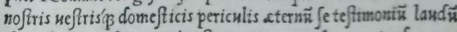

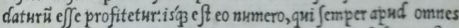

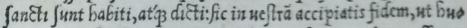
manitate neftra lenatus potius, quam acerbit ate niola-us effe uis deatur. Que de caufa pro mea

confuetudine breniter fimplicis of Qux de caufa) excufac ter'́s dixi Irdices, ea cöfido pro quod multa extra caufam Gata effe omnibus: que non fori, dixernt.

nép̧ irdiciali conjuetwdine, $\sigma$

de homixis ingenio, o communiter de ip fins findio locutus fum, ca indices à Hobis feroeffe in bonam partena accepta: $a b c 0, q$ isi indicium exercet, certe $f$ cto.

$$
\begin{gathered}
\text { DEXCVDEBAT HISPALI } \\
\text { DOMINICVS DE } \\
\text { ROBERTIS. }
\end{gathered}
$$

Imágenes tomadas del ejemplar de la BU de Salamanca BG/21825(7).

56 Hago el recordatorio de que ofrezco una transcripción diplomática literal, incluidas las erratas evidentes con blancos de palabras inadecuados y puntuación incoherente. También los textos griegos se transcriben literalmente con los diacríticos originales. 


\subsection{Variantes textuales del texto de Cicerón}

He señalado en negrita la fila que contiene las variantes exclusivas de FCS. En esta tabla aparecen en columnas sucesivas la siguiente información: 1) Posición de la variante en la edición de FCS y en la división canónica del texto de Cicerón. 2-6) Variante en las ediciones de FCS (Sevilla 1544), Latomus (Colonia 1529), Silvius (Paris 1530), Melanchthon (Hagenau 1533) y Vascosan (Paris 1539) que coincide con Hervagius (Basilea 1534). 7) Tipología de la variante (Léxica, ortográfica, tipográfica, morfológica) 8) Se señala si la variante es conjuntiva con una de las ediciones anteriores o separativa de alguna, en este último caso, precedido de 'no'.

\begin{tabular}{|c|c|c|c|c|c|c|c|}
\hline \multicolumn{8}{|l|}{ Edición } \\
\hline Pos. & Cervantes & Latomus & Silvius & $\begin{array}{l}\text { Melanch- } \\
\text { ton }\end{array}$ & $\begin{array}{c}\text { Vascosan } \\
\text { / H. }\end{array}$ & V. de Cerv. & Conj. \\
\hline $\begin{array}{l}\text { a4r, } 10 \\
(\S 1,1)\end{array}$ & $\begin{array}{l}\text { obhoruis- } \\
\text { se }\end{array}$ & $\begin{array}{l}\text { abho- } \\
\text { rruisse }\end{array}$ & $\begin{array}{l}\text { abho- } \\
\text { rruisse }\end{array}$ & $\begin{array}{l}\text { abho- } \\
\text { rruisse }\end{array}$ & $\begin{array}{l}\text { abho- } \\
\text { rruisse }\end{array}$ & Léxica & \\
\hline $\mathrm{a} 5 \mathrm{r}, 3$ & atque & atque & atque & $\mathrm{ac}$ & atque & & no Mel. \\
\hline a5r, 17 & A. & A. & Aulum & Aulum & A. & $\begin{array}{l}\text { Ortográ- } \\
\text { fica }\end{array}$ & \\
\hline a5r, 27 & Et & om. & et & om. & et & & Sil. Her. \\
\hline $\begin{array}{l}a 5 v, 9 \\
(\S 3,5)\end{array}$ & Italia tunc & Italia tunc & Italia tunc & tum Italia & Italia tunc & & no Mel. \\
\hline $\mathrm{a} 5 \mathrm{v}, 15$ & Rei p. & reip. & reip. & populi Ro. & Rei p. & & no Mel. \\
\hline$a 5 v, 26$ & $\begin{array}{l}\text { eos } \\
\text { quorum }\end{array}$ & $\begin{array}{l}\text { eos } \\
\text { quorum }\end{array}$ & $\begin{array}{l}\text { eos } \\
\text { quorum }\end{array}$ & $\begin{array}{l}\text { eiusmodi } \\
\text { quarum }\end{array}$ & $\begin{array}{l}\text { eos } \\
\text { quorum }\end{array}$ & & no Mel. \\
\hline a6r,1 & cum & cum & cum & tum & cum & & no Mel. \\
\hline a6r,2 & om. & om. & om. & in & om. & & no Mel. \\
\hline a6r,7 & fuerit & fuit & fuerit & fuit & fuerit & & Conj. Sil. \\
\hline $\begin{array}{l}a 6 r, 12 \\
(\S 3,6)\end{array}$ & vinebat & viuebat & viuebat & viuebat & viuebat & $\begin{array}{l}\text { Tipográ- } \\
\text { fica }\end{array}$ & \\
\hline $\mathrm{a} 6 \mathrm{r}, 13$ & $\mathrm{~L}$. & $\mathrm{L}$. & $\mathrm{L}$. & Lucio & $\mathrm{L}$. & & no Mel. \\
\hline a6r,15 & Drusum & Drusun & Drusum & Drusos & Drusum & & no Mel. \\
\hline $\mathrm{a} 6 \mathrm{v}, 2$ & deuinctam & deuinctam & deuinctam & deuictam & deuinctam & & no Mel. \\
\hline a6v,9 & Ciliciam & Siciliam & Sicilliam & Siciliam & Ciliciam & & Her. \\
\hline a6v,26 & om. & om. & om. & antea & om. & & no Mel. \\
\hline $\begin{array}{l}\text { a7r,5 } \\
(\$ 4,8) \\
\end{array}$ & scriptum & $\begin{array}{l}\text { adscrip- } \\
\text { tum }\end{array}$ & ascriptum & $\begin{array}{l}\text { adscrip- } \\
\text { tum }\end{array}$ & ascriptum & Léxica & \\
\hline a7r,7 & $\mathrm{L}$. & M. & $\mathrm{L}$. & M. & $\mathrm{L}$. & & Sil. Her. \\
\hline $\mathrm{a} 7 \mathrm{r}, 12$ & qui huius & huius & qui huius & huius & huius & & Sil. Her. \\
\hline $\begin{array}{l}a 7 v, 7 \\
(\$ 4,9)\end{array}$ & professus & professus & professus & om. & professus & & no Mel. \\
\hline $\mathrm{a} 7 \mathrm{v}, 13$ & Gabinii & Gabinii & Gabinii & Gabiique & Gabinii & & no Mel. \\
\hline
\end{tabular}




\begin{tabular}{|c|c|c|c|c|c|c|c|}
\hline $\begin{array}{l}\text { a7v,29 } \\
(\$ 5,10)\end{array}$ & multi & multis & multis & multis & multis & $\begin{array}{l}\text { Morfoló- } \\
\text { gica }\end{array}$ & \\
\hline $\mathrm{a} 8 \mathrm{r}, 16$ & om. & om. & ciuem & ciuem & om. & & Mel. Sil. \\
\hline $\begin{array}{l}a 8 v, 28 \\
(\$ 6,12)\end{array}$ & ita se & ita se & ita se & se ita & ita se & & no Mel. \\
\hline $\begin{array}{l}\mathrm{b} 1 \mathrm{r}, 16 \\
(\$ 6,13)\end{array}$ & temporis & temporum & temporis & temporum & temporis & & Sil. Her. \\
\hline $\mathrm{b} 1 \mathrm{r}, 21$ & adeo & ideo & adeo & ideo & adeo & & Sil. Her. \\
\hline $\begin{array}{l}b 1 v, 17 \\
(\$ 6,14)\end{array}$ & accederet & accenderet & accederet & accenderet & accederet & & Sil. Her. \\
\hline $\begin{array}{l}b 2 r, 7 \\
(\$ 7,15)\end{array}$ & $\mathrm{Ac}$ & ac & $\mathrm{ac}$ & et & $\mathrm{ac}$ & & no Mel. \\
\hline $\begin{array}{l}b 2 v, 14 \\
(\$ 7,16)\end{array}$ & alunt & agunt & agunt & agunt & alunt & & Herg. \\
\hline $\begin{array}{l}\text { b3r,2 } \\
(\$ 7,17)\end{array}$ & notu & motu & motu & motu & motu & $\begin{array}{l}\text { Tipográ- } \\
\text { fica }\end{array}$ & \\
\hline $\begin{array}{l}\mathrm{b} 3 \mathrm{r}, 14 \\
(\mathbf{8}, 18)\end{array}$ & his & his & his & iis & his & & no Mel. \\
\hline $\begin{array}{l}\mathrm{b} 3 \mathrm{v}, 22 \\
(\S 8,19)\end{array}$ & oppido & oppido & oppido & urbe & oppido & & no Mel. \\
\hline $\mathrm{b} 3 \mathrm{v}, 25$ & $\begin{array}{l}\text { post mor- } \\
\text { tem etiam }\end{array}$ & $\begin{array}{l}\text { post mor- } \\
\text { tem etiam }\end{array}$ & $\begin{array}{l}\text { post mor- } \\
\text { tem etiam }\end{array}$ & $\begin{array}{l}\text { etiam post } \\
\text { mortem }\end{array}$ & $\begin{array}{l}\text { post mor- } \\
\text { tem etiam }\end{array}$ & & no Mel. \\
\hline b3v, 29 & $\begin{array}{l}\text { repudiabi- } \\
\text { mus }\end{array}$ & $\begin{array}{l}\text { repudiabi- } \\
\text { mus }\end{array}$ & $\begin{array}{l}\text { repudiabi- } \\
\text { mus }\end{array}$ & $\begin{array}{l}\text { repudia- } \\
\text { mus }\end{array}$ & $\begin{array}{l}\text { repudiabi- } \\
\text { mus }\end{array}$ & & no Mel. \\
\hline $\mathrm{b} 4 \mathrm{r}, 6$ & et ipsi & et ipsi & et ipsi & etiam ipsi & et ipsi & & no Mel. \\
\hline $\begin{array}{l}\mathrm{b} 4 \mathrm{r}, 12 \\
(\mathbf{9 , 2 0 )}\end{array}$ & $\begin{array}{l}\text { facile prea- } \\
\text { conium }\end{array}$ & $\begin{array}{l}\text { facile prea- } \\
\text { conium }\end{array}$ & $\begin{array}{l}\text { facile prea- } \\
\text { conium }\end{array}$ & $\begin{array}{l}\text { preaco- } \\
\text { nium } \\
\text { facile }\end{array}$ & $\begin{array}{l}\text { facile prea- } \\
\text { conium }\end{array}$ & & no Mel. \\
\hline $\mathrm{b} 4 \mathrm{r}, 29$ & Lucium & $\mathrm{L}$. & Lucium & L. & $\mathrm{L}$. & & Sil. \\
\hline $\begin{array}{l}b 4 v, 15 \\
(\S 9,21)\end{array}$ & $\begin{array}{l}\text { conserua- } \\
\text { tam }\end{array}$ & seruatam & seruatam & seruatam & seruatam & Léxica & \\
\hline $\mathrm{b} 4 \mathrm{v}, 22$ & monimenta & $\begin{array}{l}\text { monu- } \\
\text { menta }\end{array}$ & monimenta & $\begin{array}{l}\text { monu- } \\
\text { menta }\end{array}$ & monimenta & $\begin{array}{l}\text { Ortográ- } \\
\text { fica }\end{array}$ & Herg. \\
\hline $\begin{array}{l}\mathrm{b} 5 \mathrm{r}, 5 \\
(\mathbf{9}, \mathbf{2 2})\end{array}$ & honos & honos & honos & honor & honos & & \\
\hline b5r,11 & rudium & rudem tum & rudium & rudem & rudium & & Sil. Her. \\
\hline $\begin{array}{l}\mathrm{b} 6 \mathrm{r}, 4 \\
(\$ 10,25)\end{array}$ & Sylla & Sylla vero & Sylla & Sylla vero & Sulla & & Sil. \\
\hline $\mathrm{b} 6 \mathrm{r}, 7$ & cum ei & cum ei & cum ei & cui cum & cum ei & & no Mel. \\
\hline b6r, 13 & iubere & iubere & iubere & iussit & iubere & & no Mel. \\
\hline $\begin{array}{l}\mathrm{b} 6 \mathrm{v}, 6 \\
(\$ 10,25)\end{array}$ & Ipsi illi & Ipsi illi & Ipsi illi & ipsi & Ipsi illi & & no Mel. \\
\hline
\end{tabular}




\begin{tabular}{|l|l|l|l|l|l|l|l|}
\hline $\mathrm{b} 6 \mathrm{v}, 7$ & in illis & in illis & in illis & illis & in illis & & no Mel. \\
\hline $\mathrm{b} 6 \mathrm{v}, 10$ & in eo & In eo & In eo & et in eo & in eo & & no Mel. \\
\hline $\begin{array}{l}\mathrm{b} 6 \mathrm{v}, 17 \\
\mathbf{( \$ 1 1 , 2 7 )}\end{array}$ & $\begin{array}{l}\text { Monimen- } \\
\text { torum }\end{array}$ & $\begin{array}{l}\text { monumen- } \\
\text { torum }\end{array}$ & $\begin{array}{l}\text { monumen- } \\
\text { torum }\end{array}$ & $\begin{array}{l}\text { monumen- } \\
\text { torum }\end{array}$ & $\begin{array}{l}\text { monimen- } \\
\text { torum }\end{array}$ & $\begin{array}{l}\text { Ortográ- } \\
\text { fica }\end{array}$ & Herg. \\
\hline $\begin{array}{l}\mathrm{b} 7 \mathrm{r}, 24 \\
\mathbf{( \$ 1 1 , 2 9 )}\end{array}$ & eisdem & eisdem & iisdem & iisdem & eisdem & & Herg. \\
\hline $\mathrm{b} 7 \mathrm{r}, 25$ & suas & suas & suas & suos & suas & & no Mel. \\
\hline $\mathrm{b} 7 \mathrm{v}, 2$ & Et & et & et & ac & et & & no Mel. \\
\hline $\mathrm{b} 7 \mathrm{v}, 27$ & sunt & sunt & sunt & est & sunt & & no Mel. \\
\hline $\begin{array}{l}\mathrm{b} 7 \mathrm{v}, 29 \\
\mathbf{( \$ 1 2 , 3 0 )}\end{array}$ & $\begin{array}{l}\text { pertine- } \\
\text { bunt }\end{array}$ & $\begin{array}{l}\text { pertine- } \\
\text { bunt }\end{array}$ & $\begin{array}{l}\text { pertine- } \\
\text { bunt }\end{array}$ & pertinebit & $\begin{array}{l}\text { pertine- } \\
\text { bunt }\end{array}$ & & no Mel. \\
\hline $\begin{array}{l}\mathrm{b} 8 \mathrm{r}, 2 \\
(\mathbf{1 2 , 3 1 )}\end{array}$ & conservate & conservare & conservate & conservate & conservate & & no Lat. \\
\hline
\end{tabular}

\subsection{Argumentum (Latomus, Colonia 1529, [h. C3v])}

Argumentum in orationem pro Archia.

A. Licinius Archias poeta, cum beneficio L. Luculli optimatis viri, in Heracliensium civitatem ascriptus, lege Syllani et Carbonis Romanus civis factus esset: postulatus est ea de re a Graccho quodam et cum causam apud iudices diceret, magno literatorum hominum concursu: defensus est a Cicerone hac luculentissima oratione: quae artium humanitatis laudibus est insignis.

\subsection{Argumentum (Silvius, París 1530, [h. A4v])}

A. Licinius Archias Antiochie natus, poeta Graecus, ingenii gloria praestabilis in italiam venit, quae tum Grecarum disciplinarum plena erat. Itaque hunc Tarentini, Rhegyni, Locrenses \& Neapolitani civitate donaverunt. Postea Romam C. Mario et Q. Catulo coss. venit. Eum Luculli domum suam receperunt, quem alii quoque viri clarissimi coluerunt. Satis longo intervallo cum L. Lucullo Praetore in Siciliam profectus est. Inde cum eodem Lucullo decedens venit Heracleam, quae ciuitas cum populo Ro[mano] foederata erat. Ascribi se in eam ciuitatem voluit. Id cum per se, tum Luculli gratia ab Heracliensibus impetravit. Postea Romana civitate Syllani \& Carbonis lege donatus est, quae erat,ut cives Romani essent, qui ex foederatis civitatibus ascripti fuissent, si tum quum lex ferebatur in Italia domicilium habuissent, et si .lx. diebus apud Praetorem professi essent. Hunc Archiam iam senem quidam nomine Gracchus accusavit, quod cum civis non esset, se pro cive gereret. Eum civem non esse probavit, quod Heracleae adscriptus non esset (id enim in publicis Heracliensium tabulis scriptum esse negabat) quod domicilium in Italia non habuerit, quod apud Praetorem professus non sit, quod a Censoribus census non fuerit. Hunc autem Cicero hac oratione defendit, quia eo praeceptore primo puer usus fuerat. Ostendit igitur eum in civitatem ab Heracliensibus adscitum fuisse, et credendum potius Lucullo et Heracliensibus id confirmantibus, quam tabulis, si extarent, quae tamen bello Italico exustae fuerant. Domicilium Romae: eum habuisse, et professum esse 
apud Praetorem Q. Metellum probat. Quod a Censoribus census non fuerit, id purgat. Cur tantopere Archia delectetur, quae cum ex aliis studiis tum maxime ex poeticis et voluptas et utilitas capiatur, abunde docet. Postremo concludit per enumerationem. Genus causae iudiciale. Status coniecturalis est.

\subsection{Argumentum (Cervantes Salazar, Sevilla 1544, hh. [a2v]-a3r)}

Francisci Cervantes Sanazari in M. T. C. orationem Pro Archia poeta argumentum.

Archia dictio Graeca latine principatum sonat, quo nomine viri nonnulli illustres extitere, inter quos fuit unus Archias poeta Graecus, qui in Italiam veniens quae tum graecis litteris pollebat ob singulare ingenium a Locrensibus, Tarentinis, Rheginis, et Neapolitanis civitate donatus, Consulibus. C. Mario \& Q. Catullo Romam est profectus: ubi cum in gratia clarissimorum virorum vixisset, praecipue a Lucullis magno in praecio habitus. L. Lucullum quaestorem in Asiam, Consulem etiam in Asiam, Praetorem in Siciliam commitatus est. Unde discedens una cum Lucullo Heracleam venit, ibique cum sua virtute, tum Luculli autoritate ut in civitatem ascriberetur, a Locrensibus impetravit, idque lege Syllani \& Carbonis, qua iis civitatis ius dabatur, qui confoederatis civitatibus ascripti, et apud Praetorem professi essent. Huic postea iam seni quidam Gracchus litem movit, quod civis non esset, cur vero id fecerit Gracchus, non constat, defenditur tamen a Cicerone Archias, cui in primis familiaris fuerat poeta. Praeter hunc (ne hoc etiam lectorem lateat et late explicemus, quod supra indicavimus) fuit alius Archias Tarentinus Philosophus, qui floruit Platonis tempore et a multis non Archias, sed Architas dicitur, fuit ali[u]s musicus Mytileneus et alius epigrammaton scriptor et alius qui de agri cultura scripsit, fuit et Archias preco celeberrimus, qui tres ordine Olympiadas vicit, fuit et Archias qui Syracusas in Sicilia condidit, quorum omnium authores sunt. Pedianus, Antonius Luscus, Volaterranus, Suidas, et Polux. Volui scriptum a doctis antea argumentum meis verbis vestire, ut tanquam novum placeret. addidi etiam nonnulla, quae ipsi volentes forsan reliquerunt. Causae genus iudiciale est, cui (quia Cicero in laudes Archie divertitur) mixtum est demostrativum. Status causae (in quo tota causa consistit) coniecturalis est. Quaeritur enim an civis sit Archias. Sunt autem status tres, coniecturalis, legitimus, et iuridicialis. quorum quaestiones sunt, an sit, quid sit, quale sit. Oportet autem status meminisse lectorem, ut reliqua omnia facile intelligat.

\subsection{Dispositio (Cervantes Salazar, Sevilla 1544, hh. a3r-[a3v])}

Se marcan en negrita las partes coincidentes literalmente con las de Melanchthon.

M.T.C. orationis Pro Archia poeta dispositio ex probatissimis authoribus per eundem breviter| excerpta.

Oratio haec primum omnium, exordio, narratione, confirmatione confutationi permixta, et per oratione constat. Sed quo pacto partes hae tractentur, ut recte disposita videatur oratio, paucis accipe. Locus exordii sumptus est ex communi loco, scilicet ex officio referendae gratiae: et hac ex propositione exordium totum nascitur. Cicero enim refert se debere Archiam defendere ut ei gratiam rependat. Hanc periodum sequitur altera, q[uae] probationem huius sententiae continet, quia Archias adiuvit dicendi studium. Tertio est addita conclusio, aequum enim est, ut qui auxilio Archiae 
alios iuvi, opituler etiam ipsi Archiae. Deinde sequuntur occupationes duae, prima quomodo potest poeta patrocinio esse oratori, altera est, ineptum esse in foro de studiis agere. Archiam vero civem esse principalis est in tota oratione propositio, eaque statum constituit. post exordium mox succedit narratio, quae historiam vitae Archiae continet et peregrinationum, quibus indicat, quomodo civitatis ius fuerit consequtus, in fine narrationis syllogismus est quo narratio clauditur. narrationem confirmatio sequitur, cuius ut vim intelligas, necesse est syllogismi sis memor, omnes inscripti et cetera. Maior in syllogismo nil habet ambigui, minor vero incerta est, proptereaque in ea probanda confirmatio tota versatur, locos summens a testibus a tabulis et coniecturis, quod Heracleae ascriptus et professus sit. accedit postea verisimile ex minori. multi non ita docti. Postremo addit signa Romani civis. adiit inquiens in hereditates, testamentum fecit et cetera. Demum quia sterilis et ieiuna causa erat, divertitur ad locum communem de laude, ubi litteras commendans, Archiam laudat et dignum civitate demonstrat. Sequitur post, occupatio, tu ne igitur fateris et cetera. Cui respondet per concessionem, finales tres causas subiciens. obiecto statim sequitur, num igitur et cetera. Primum concessione utitur et addit rationem, deinde subicit correctionem, quam probat exemplis, hactenus recitavit argumenta sumpta a persona Archiae, quod retinendus sit, quia poeta. Nunc subicit exempla eodem pertinentia, ab exemplo aliarum civitatum et aliorum principium, quibus poetae cari fuerunt. Postea locus communis est de laude, trahimur omnes et cetera. Quae sententia Bruti et Fulvii exemplis comprobatur. Postremo orationem totam brevis conclusio claudit, breviter totius causae argumenta repetens. affectus et excusatio (quod multa extra causam dixerit) orationi finem imponunt.

\subsection{Relación de ediciones del Pro Archia anteriores a Cervantes Salazar ${ }^{57}$}

\begin{tabular}{|c|c|c|c|c|c|}
\hline Año & Ciudad de ed. & Editor / Impresor & $\mathrm{N}^{\mathrm{o}} \mathrm{USTC}$ & $\mathrm{N}^{\mathrm{o}}$ ISTC & $\mathrm{N}^{\circ} \mathrm{GW}$ \\
\hline 1471 & Roma & $\begin{array}{l}\text { K. Schweynheym y A. } \\
\text { Pannartz }\end{array}$ & 995944 & ic00541000 & 06761 \\
\hline 1484 & Bamberg & J. Sensenschmidt & 743986 & ic00550800 & 06783 \\
\hline 1494 & Reutlingen & J. Otmar & 743987 & ic00551000 & 06784 \\
\hline 1495 & Leipzig & G. Böttiger & 743988 & ic00551050 & 06785 \\
\hline 1498 & Leipzig & J. Tanner & 743989 & ic00551100 & 06786 \\
\hline 1506 & Venezia & C. Pensi & 822073 & & \\
\hline 1509 & Leipzig & J.Tanner & 649842 & & \\
\hline 1514 & Leipzig & W. Stöckel & 649838 & & \\
\hline 1515 & Leipzig & W. Stöckel & 649839 & & \\
\hline 1517 & Leuven & T. Martens & 403376 & & \\
\hline 1518 & Leipzig & W. Stöckel & 649841 & & \\
\hline 1518 & Kraków & H. Wietor & 240622 & & \\
\hline
\end{tabular}

Esta lista pretende recoger todas las ediciones exentas del Pro Archia, así como las más significativas de las que incluyen el Pro Archia del periodo anterior a 1544. Se cita el número de referencia del USTC y los de ISTC y $G W$ en el caso de los incunables. 


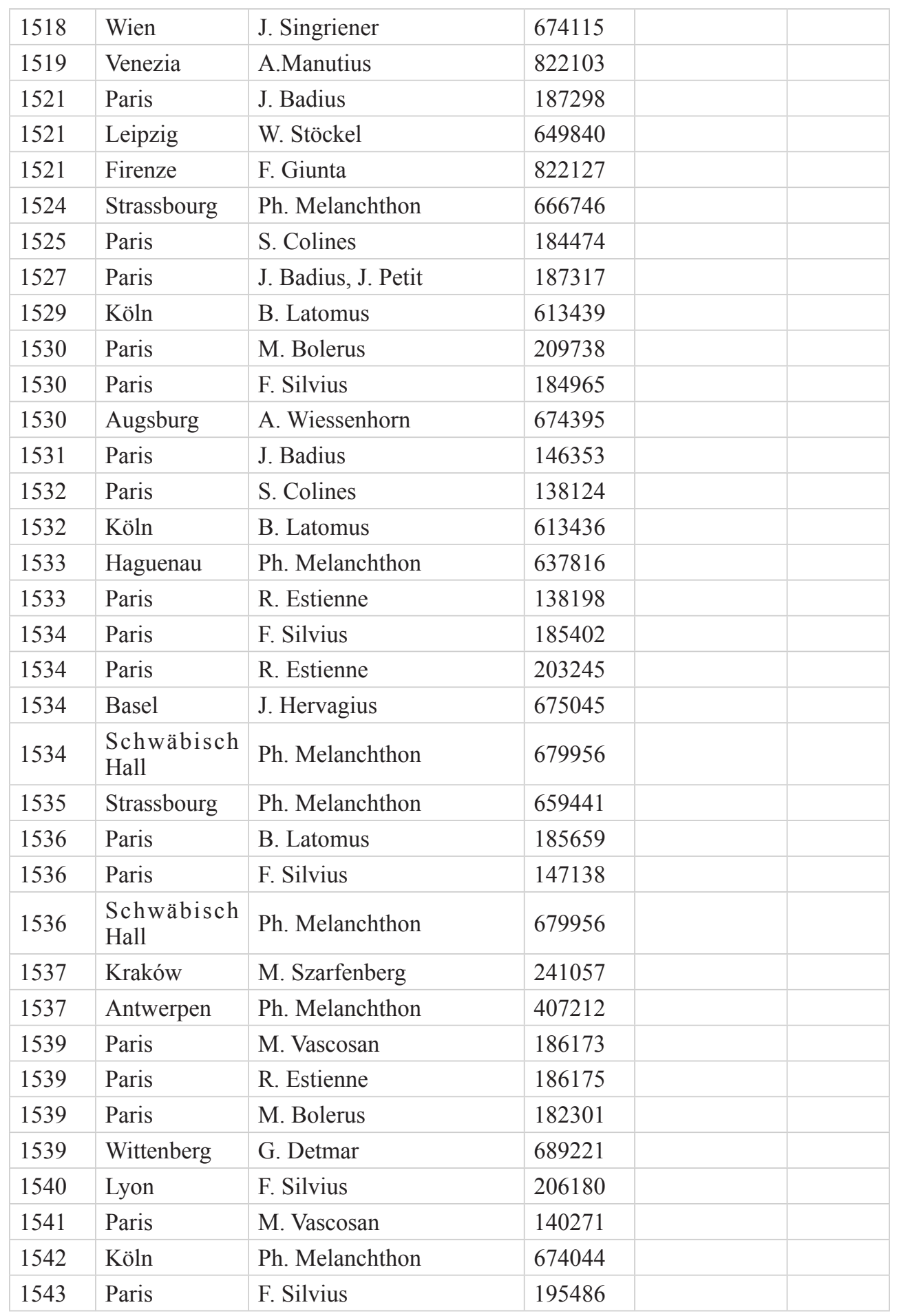

